\title{
CMPA refocuses on preventing complaints
}

\author{
Cite as: CMAJ 2017 June 12;189:E809-10. doi: 10.1503/cmaj.1095435
}

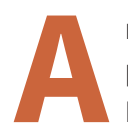
massive increase in patient complaints has the Canadian Medical Protective Association (CMPA) expanding the help it provides doctors to avoid regulatory and legal trouble.

Complaints to hospitals and medical regulatory colleges have increased exponentially in recent years, says $\mathrm{Dr}$. Todd Watkins, CMPA managing director of physician services. "There's been a 10-12\% rise in college and hospital matters yearover-year for the last two to three years, compared to a fairly consistent number of lawsuits."

College matters brought to CMPA have almost doubled since 2006 to more than 4000 new cases annually, while hospital matters have increased by $85 \%$ to more than 1000 new cases a year. At the same time, legal actions against CMPA members have declined by about 5\%, with 862 new cases in 2015.

Watkins attributes these trends to hospitals and medical regulators improving their complaints processes, making it easier for patients to seek recourse outside the courts. Increasing scrutiny of the profession by media and government has driven colleges to be "a lot more diligent and some are seeing higher volumes of complaints as a result," he says.

The growing media spotlight on patient safety has also shifted public perceptions and expectations of care, he says. "The reports that patients and the public see about physicians continue to be very nega-

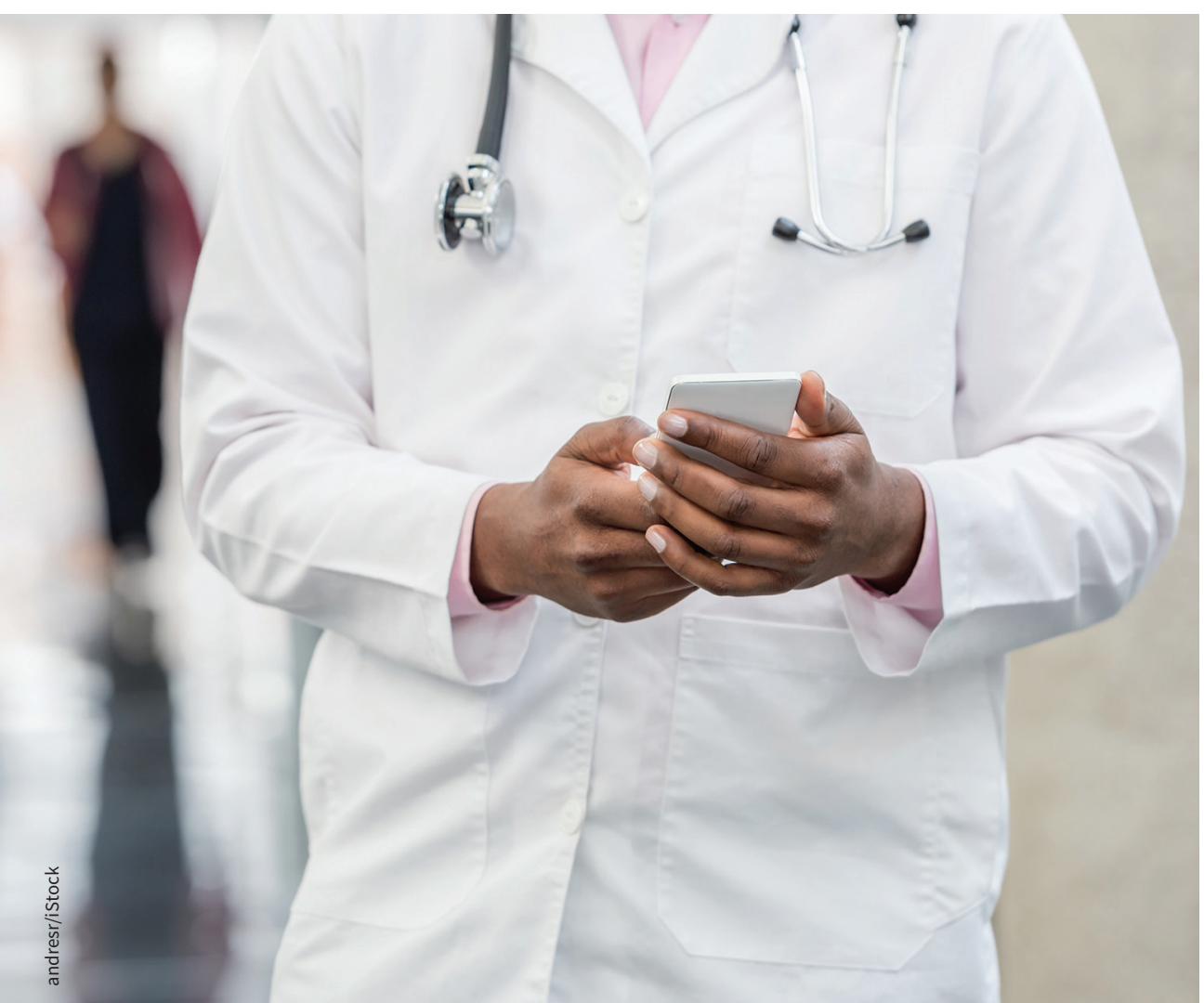

The CMPA is overhauling its phone support and education programs in response to increasing complaints against doctors. tive and I think that's driving an increase in the number of complaints as well."

In response, CMPA is refocusing. "It's clear we have the ability to do more than we have in the past," particularly when it comes to preventing repeat complaints, Watkins says.

CMPA receives more than 200 calls a day from doctors seeking advice, but the support it provides is largely one-off. Starting in the fall, CMPA will track those interactions more closely so it can provide more customized and ongoing support. For example, if a member has a pattern of communication problems, "we'd have a conversation about their needs in that area and provide them with a list of resources, and be there for them on a long-term basis with further guidance," Watkins explains.

The aim is to identify earlier the "smaller proportion of members typically responsible for a larger proportion of the medical legal files." In addition to expanding its phone support, CMPA is working on intensive three-day education programs for these physicians.

The association is also piloting a one-day course to equip medical trainees with the skills they need to avoid legal trouble, including "things like communication, disclosure of adverse events and how to do consent," Watkins says. Two medical schools are involved in the pilot, but CMPA aims to expand the program across the country.

These new initiatives are part of a larger overhaul of CMPA's education program to focus on safe medical care. "We have an incredible amount of data about what goes right and what goes wrong in the system, and we have all the knowledge we glean from our cases, and we're able to put that into our safety program," Watkins says.

Ontario and Quebec have seen the greatest increases in college complaints, even though patients in Quebec tend to file more complaints through hospitals. Watkins says that the increases predate the 
recent conflicts between doctors in these provinces. However, many doctors are worried about the impact of Ontario's Bill 87, which would impose tougher sanctions on sexual impropriety and remove colleges' discretion in meting out punishment.

Some argue the bill will make doctors overcautious, particularly when it comes to physical exams or treating patients with mental illness, out of fear that a misinterpreted touch might ruin their careers. "Physicians generally are worried about accountability and changes to self-regulation," Watkins says.

Doctors are also anxious about the risks involved in providing or refusing medical aid in dying, he says. CMPA has had over 500 requests for advice since assisted death became legal last year.

CMPA will release its annual report in June.

Lauren Vogel, CMAJ 